\title{
Subject and stimulus variables in short-term recall and span of apprehension
}

\author{
L. W. BUCKALEW and R. S. HICKEY \\ Alabama A \& M University, Normal, Alabama
}

\begin{abstract}
Research has suggested that subject and stimulus variables are related to differential performance in perceptual tasks involving short-term recall. This study explored sex, race, and stimulus-duration variables as they related to memory efficiency. Numbers of from two to eight digits were randomly presented at $1 / 30$ - and $1 / 60$-sec exposures. College students $(N=86$, with 17 of each sex/race combination) reproduced digits immediately after slide presentation for 14 trials. A three-way ANOVA indicated significant main effects of sex, race, and exposure and a significant interaction of sex and race. In seven of the eight group/exposure combinations, significant negative correlations between stimulus complexity and recall evidenced a span-ofapprehension phenomenon.
\end{abstract}

Perceptions and memory are research topics rooted in the origins of psychology. Initiation of memory research, using nonsense syllables to avoid contamination by meanings present in ordinary words, is traditionally credited to Ebbinghaus. Perceptual research owes much to Titchner's position that a perception depends on stimulus quality (degree), intensity (duration), and attention (clarity). Concern with discrimination of rapidly presented stimuli, although dated to the early 1860 s by McConnell, Cutler, and McNeil (1958), gained impetus through the work of Thorndike and Rock (1934) and Miller (1939). The integration of perceptual and memory processes was greatly facilitated through Broadbent's (1958) postulate of two kinds of learning (short term and long term), followed by Sperling's (1960) formalized treatment of iconic memory and span of apprehension as the number of items perceived and remembered in a single exposure. An interesting and controversial combination of perception, memory, and span of apprehension was offered by McGinnies (1949) under the rubric of subliminal perception/perceptual defense.

Short-term-memory functions appear to be relatively important and differentiating of human performance functions. As noted by Garner (1962), the more complex, uncertain, or structurally sophisticated a stimulus is, the lower the response efficacy. Particularly for rapidly presented material, McConnell et al. (1958) and Sacheim, Packer, and Gur (1977) surmised that subject and stimulus variables may play major roles in

This effort was, in part, supported by Grant SPI80-10733 from the National Science Foundation through Howard University. Appreciation is expressed to Donald King, Department of Psychology, Howard University, for his thoughtful comments and critique. Address reprint requests to L. W. Buckalew, Box 200, Department of Psychology, Alabama A \& M University, Normal, Alabama 35762. the perception and memory of stimulus material. Appreciating the potential impact of stimulus complexity and subject variables on perception and short-term memory, this study explored the effects of stimulus-exposure time and complexity and of subject sex and race on perception measured by short-term recall and apprehension span. Of particular interest was the relationship of span of apprehension for alphabetic (Sperling, 1960) versus numerical material.

\section{METHOD}

\section{Subjects}

Volunteer psychology students $(\mathrm{N}=68$, with 17 of each sex/race combination-black, white, male, female) participated. They ranged in age from 18 to 27 years, with sex/race group mean ages of 19.5 to 22.3 years, and were in the sophomore or junior year.

\section{Apparatus}

A Kodak Carousel projector with collar-attached tachistoscopic shutter projected stimulus slides onto a standard screen; the slides showed two to eight random Arabic numerals. Each of 14 slides ( 2 each of two through eight digits) had a different combination of numbers. A single five-digit slide was used, open shutter, to familiarize the subjects with contrast, digit size, and screen placement. Data sheets identifying the 14 trials by letter (A-N) were used to record responses.

\section{Procedure}

The subjects were tested in random groups of 10 to 15 , seated in an arc approximately $10 \mathrm{ft}$ from the screen. Those needing glasses were asked to use them. Prior to testing, the subjects were told that the purpose of the experiment was to determine how much information the brain could assimilate with minimal stimulus exposure. Instructions were to concentrate on the screen, because the numbers would appear only briefly, and to immediately record those numbers perceived. After the practice exposure, trials were announced by letter, with "ready" preceding each exposure and with a 20 -sec intertrial interval for recording "remembered" digits. The stimuli were presented randomly at $1 / 30$ or $1 / 60 \mathrm{sec}$, with seven trials (two to eight digits) under each exposure condition. Both stimulus complexity (number of digits) and exposure duration (1/30 or $1 / 60 \mathrm{sec}$ ) 
were random, and each possible combination of complexity/ duration was presented. The scoring of data sheets was blind, with a correct response accorded each stimulus digit in the proper sequence ( 35 possible per exposure condition).

\section{RESULTS}

For each subject, the total number of correct digits for each exposure condition was tabulated. A three-way ANOVA (sex $x$ race $x$ exposure) applied to these data, as presented in Table 1 , analyzed for sex, race, and exposure condition (stimulus duration) main effects and related interactions. Group (sex/race) mean performance comparisons are shown in Figure 1. To explore the effects of stimulus complexity, the mean percentage of correct digits for each trial, representing a different combination of digits and duration, was computed for each group and condition. Given no significant interactions between exposure duration and sex or race, correlations for each sex/race group were computed, using a log transformation of the stimulus digits $(\mathrm{X})$ variable, for complexity versus efficiency variables. For the $1 / 30$-sec

Table 1

Summary Analysis of Variance: Total Digits Reported as Functions of Exposure Time (A), Sex (B), and Race (C)

\begin{tabular}{lrcrc}
\hline $\begin{array}{l}\text { Source of } \\
\text { Variation }\end{array}$ & $\begin{array}{r}\text { Sum of } \\
\text { Squares }\end{array}$ & $\begin{array}{c}\text { Degrees of } \\
\text { Freedom }\end{array}$ & $\begin{array}{c}\text { Variance } \\
\text { Estimate }\end{array}$ & \multicolumn{1}{c}{$\mathrm{F}$} \\
\hline A & 339.89 & 1 & 339.89 & $11.43^{* *}$ \\
B & 150.36 & 1 & 150.36 & $5.06^{*}$ \\
C & 524.19 & 1 & 524.19 & $17.63^{* *}$ \\
A x B & 5.36 & 1 & 5.36 & .18 \\
A x C & 35.00 & 1 & 35.00 & 1.18 \\
B x C & 455.89 & 1 & 455.89 & $15.33^{* *}$ \\
A x B x C & 1.70 & 1 & 1.70 & .06 \\
Within & 3805.47 & 128 & 29.73 & \\
Total & 5317.86 & & & \\
\hline
\end{tabular}

${ }^{*} p<.05 . \quad{ }^{* *} p<.01$.

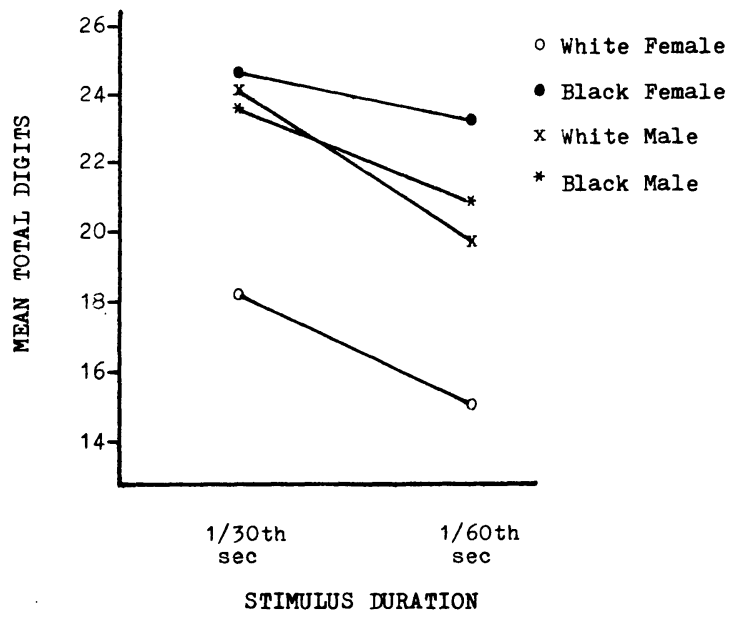

Figure 1. Comparative group performance in total number of digits correctly reported under two different stimulus-duration conditions. exposure condition, coefficients (r) ranged from -.809 to -.961 , all of which were significant $(\mathrm{p}<.01)$ under the one-tailed-test assumption of decreasing proficiency with increasing complexity. For the $1 / 60$-sec condition, black females' (-.947) and black males' $(-.879)$ coefficients were significant $(\mathrm{p}<.01)$, with white males' $(-.741)$ coefficients being significant at a lesser level $(\mathrm{p}<.05)$ and white females' $(-.390)$ coefficients being nonsignificant.

\section{DISCUSSION}

Sex, race, and stimulus duration were variables of clear consequence in this rapid-exposure, short-term-memory experiment. However, the significant interaction between sex and race readily accounts for much of the variance in respective main effects, as reflected in Table 1. Although the data shown in Figure 1 appear to support suggestions of differential subject variables in similar tasks (McConnell et al., 1958; Sacheim et al., 1977), it may be surmised that the appreciably poorer performance of the white female group is largely responsible for apparent sex or race effects. This position is supported further by the particularly weak correlation $(-.390)$ between stimulus complexity and recall/perception for white females in the $1 / 60$-sec exposure condition. Further clouding the interpretation is the methodological inability to separate perceptual effects from short-term-memory/recall effects.

Irrespective of subject variables, and supportive of the McConnell et al. (1958) position that the accuracy of a perception increases as the stimulation approaches a supraliminal level, the Table 1 data clearly depict a significant effect of stimulus duration on recall performance. As seen in Figure 1, there was a definite performance superiority in the longer $(1 / 30-\mathrm{sec})$ exposure duration for all groups. Furthermore, and generally true of both exposure conditions and all subject groups, the strong negative correlations between recall performance and stimulus complexity neatly supported Garner's (1962) surmisal that performance decreases with increases in stimulus complexity. Of note, Sperling (1960) used the full-report procedure and found notably deteriorated performance after four or five letters were used. The present data suggest that, for numbers, five or six digits may be a critical complexity configuration for recall efficiency.

Although this study does not offer altogether unexpected findings, several supplemental benefits were noted. The experiment is easily organized, procedurally simple, and well accepted by students and may be used to introduce such instructional topics as subliminal perception, perceptual defense, memory icons, short-term memory, and the ability of the brain to integrate material with minimal exposure. With minimal procedural restructuring, a related paradigm can be employed to demonstrate related topics of the meaningfulness of material, subliminal advertising, the role of repetition, and the phenomenon of déja vu. As presently reported, the comparatively poor performance of white female subjects may deserve further exploration.

\section{REFERENCES}

Brondbent, D. E. Perception and communication. New York: Pergamon Press, 1958.

GARner, W. R. Uncertainty and structure as psychological concepts. New York: Wiley, 1962.

McConnell, J. V., Cutrer, R. L., \& McNeil, E. B. Subliminal stimulation: An overview. American Psychologist, 1958, 13, 229-242.

McGinnies, E. Emotionality and perceptual defense. Psychological Review, 1949, 56, 244-251. 
Mille R, J. G. Discrimination without awareness. American Journal of Psychology, 1939, 52, 562-578.

Sacheim, H. A., Packer, I. K., \& Gur, R. C. Hemisphericity, cognitive set, and susceptibility to subliminal perception. Journal of Abnormal Psychology, 1977, 86, 624-630.

Sperling, G. The information available in brief visual presenta- tions. Psychological Monographs, 1960, 74(11, Whole No. 498).

ThorNDike, E. L., \& Rock, R. T. Learning without awareness of what is being learned or intent to learn it. Journal of Experimental Psychology, 1934, 17, 1-19.

(Manuscript received for publication September 1, 1983.) 